\title{
Estética e ideología en las secuencias de créditos de las series El puente y Mindhunter
}

Víctor Lope Salvador | v.lopesalvador@gmail.com Universidad de Zaragoza

Palabras clave

"Audiovisual”; "estética"; "ideología”;

"narración"; "secuencia de créditos";

"teleserie".

Sumario

1. Introducción.

2. Fundamentación teórica. 2.1. Problemas

teóricos respecto de la ideología. 2.2. Sobre la

estética y sus implicaciones ideológicas. 2.3.

La ideología en la narración audiovisual. 2.4.

La estética de los créditos.

3. Metodología.

4. Resultados y discusión. 4.1. El caso de

El puente.4.2. El caso de Mindhunter. 4.3.

Discusión.

5. Conclusiones.

6. Bibliografía.

\section{Resumen}

Este trabajo es un análisis sobre los aspectos estéticos e ideológicos de dos secuencias de créditos correspondientes a las series El puente y Mindhunter. El análisis se aborda a partir de una sintética fundamentación teórica sobre los contenidos ideológicos localizables en los textos audiovisuales narrativos. La metodología empleada deriva de esa síntesis teórica que establece una diferenciación de dos niveles ideológicos: el de la formulación precisa de proclamas en torno a cualquier tema y el de la creación de sustratos difusos que se extienden por la vía de la estetización y de forma no tan consciente. Así, el método empleado es el del

análisis minucioso, como un deletreamiento, guiado por las búsquedas tanto de motivos vinculados con el universo narrativo, como de posibles asociaciones, de metáforas y también de adscripciones a ciertos modos de representación y a ciertas tendencias estéticas. Las secuencias de créditos de las series actuales resultan ser un terreno idóneo para analizar esta vinculación entre estética e ideología. En las dos que se analizan, se detectan, como rasgos esenciales de su escritura, el horror, la oscuridad, el miedo, el dolor, la falta de horizonte y, en general, un tono emocional pesimista.

\section{Cómo citar este texto:}

Víctor Lope Salvador (2018): Estética e ideología en las secuencias de créditos de las series Elpuente y Mindhunter, en Miguel Hernández Communication Journal, nº (2), pp. 379 a 400. Universidad Miguel Hernández, UMH (Elche-Alicante). DOI: http://dx.doi.org/10.21134/mhcj.v0i9.255 


\section{Aesthetics and ideology in the credit sequences of the series The Bridge and Mindhunter}

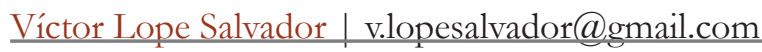

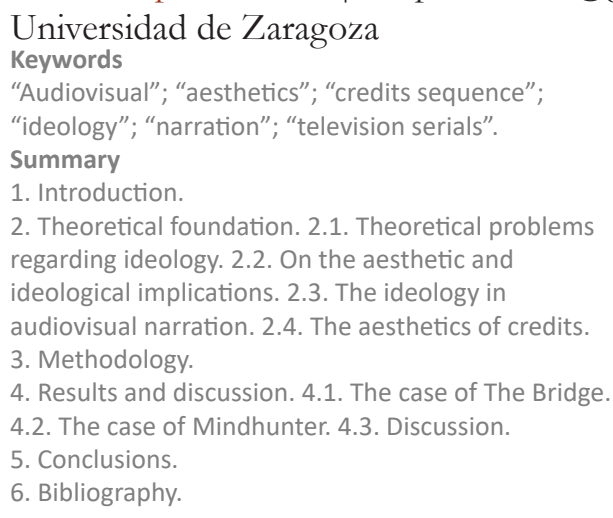

\section{Abstract}

This work analyses the aesthetic and ideological aspects of two credit sequences corresponding to the series: The Bridge and Mindhunter. A theoretical synthetic basis is used to analyse the ideological contents that can be found in the narrative audio-visual texts. The methodology applied stems from that theoretical synthesis that differentiates between two ideological levels: the precise formulation of proclamations about any topic, and the creation of diffuse substrates that spread, by means of an aestheticizing process, and rather unconsciously. Thus, a thorough analysis is the chosen method, a breakdown into significant elements, guided by the search for reasons linked to the narrative universe, as well as for possible associations, metaphors, and for affiliations to certain modes of representation and certain aesthetic tendencies. Today's credit sequences form the ideal ground to analyse this link between aesthetics and ideology. In the two series analysed, the main features detected in the writing are, horror, darkness, fear, pain, lack of horizon and, in general, a pessimistic emotional tone.

\section{How to cite this text:}

Juan Carlos Gómez Muñoz, Andrés Ballesteros Palencia (2018): Graphic content generated by citizen photographers and published in the media. Photographer Jacobo Méndez Díez in El País, in Miguel Hernández Communication Journal, nº (2), pp. 379 a 400. Universidad Miguel Hernández, UMH (ElcheAlicante). DOI: http://dx.doi.org/10.21134/mhcj.v0i9.255 


\section{Introducción}

Las obras audiovisuales narrativas constituyen textos complejos con los que los espectadores nos relacionamos en distintos niveles cognitivos y emocionales. Dentro de ese campo relacional están los efectos ideológicos. Procedemos a revisar un conjunto de postulados teóricos y metodológicos relevantes en torno a la definición de lo ideológico, al reconocimiento de sus funciones y al estudio de sus complicidades estéticas. Nuestro punto de partida es la asunción de que la narración audiovisual dispone de los conflictos, de los personajes o de las relaciones causales como contenidos capaces de albergar diferentes posicionamientos ideológicos. Y añadimos, más allá de lo narratológico, otro elemento influyente para la ideología cual es la estética, un componente específico de las propias formas de la escritura audiovisual.

Consideramos especialmente adecuado el análisis textual para abordar las polifonías de estética e ideología que caracterizan a las secuencias de créditos de las series Elpuente (Bron/Broen, 2011, SVT 1) ${ }^{1}$ y Mindhunter (2017, Netflix) ${ }^{2}$. La hipótesis que el análisis va a tratar de confirmar es esta: son secuencias, fotográficamente muy elaboradas, que se recrean en la relativización significante, en la deconstrucción gozosa de lo estable, llegando a proclamar el horror como única certeza.

\section{Fundamentación teórica}

\subsection{Problemas teóricos respecto de la ideología}

Sin duda, uno de los grandes temas de interés en los estudios sobre comunicación es el de las relaciones entre el momento histórico-social y los contenidos de las producciones audiovisuales narrativas. Esos vínculos son muy variados y se pueden abordar desde múltiples perspectivas; pero hay uno que reviste ciertas dificultades teóricas y metodológicas: el de los efectos ideológicos de la narración audiovisual. No faltan las advertencias acerca de esta circunstancia:

...existen correlaciones aún no lo suficientemente estudiadas entre la ideología que proyectan los productos culturales y su influencia en la sociedad o bien sobre la influencia de la sociedad en la construcción ideológica de los productos culturales. En cualquier caso, y sea como fuere, queda selva por explorar (Cortés, 2014: 49).

Los intentos de destilar un mensaje ideológico unívoco e inequívoco a partir de obras audiovisuales complejas, no pocas veces contradictorias, corren el riesgo de generar simplificaciones en sí mismas ideológicas y, precisamente por eso, no excesivamente rigurosas. Veamos un ejemplo de esto a propósito de House of cards (2013, Netflix):

...la serie estadounidense no es una crítica hacia el sistema político y democrático de los Estados Unidos, sino un rechazo hacia aquel que se presenta como lo contrario. A modo de ejemplo, representa que los políticos pueden dejarse llevar por la corrupción en algunas ocasiones pero que suelen pensar en el conjunto de la población, siendo el representante no político (Frank Underwood) el verdadero mentiroso, elitista, egoísta y corrupto (Donstrup, 2017: 59).

Sirva lo anterior como indicio de las carencias que se pueden encontrar en los trabajos académicos a la hora de analizar los textos audiovisuales en busca de sus contenidos y/o efectos ideológicos. La metáfora de la selva mencionada por Cortés (2014: 49) da una idea de los problemas y de la maraña discursiva ambiental en la que no es fácil meter el bisturí del análisis para separar lo

${ }^{1}$ Bron/Broen: https://www.imdb.com/title/tt1733785/

${ }^{2}$ Mindhunter: https://www.imdb.com/title/tt5290382/ 
ideológico de lo que no lo es. Es responsabilidad de las ciencias sociales y de las humanidades acometer nuevos intentos de clarificación teórica sobre esta cuestión. De forma limitada y modesta, vamos a realizar aquí un repaso por ciertos postulados confiando en obtener algunos instrumentos útiles para avanzar en la selva mencionada.

Un notable estudioso del tema como van Dijk afirma que "El conocimiento es la creencia compartida por los miembros de una comunidad social o cultural, la 'comunidad de conocimiento' o "comunidad epistémica' " (van Dijk, 2005: 289). De hecho, está introduciendo en esa definición de conocimiento un componente ideológico y, siendo la creencia el componente esencial tanto para el conocimiento como para la ideología, según sus postulados, llama la atención que no intente explorar lo que se juega en torno a ella, exploración que sería también de competencia psicológica y antropológica.

Las ideologías son por definición sociales, y comunes para los miembros de un grupo. He asumido antes que esas ideologías son generales, abstractas y fundamentales, y que organizan otras formas de representaciones, como por ejemplo las actitudes. Pueden implicar categorías abstractas de grupo, como por ejemplo relaciones de grupo o identidades, pero también objetivos colectivos, normas o valores. Por esta razón a menudo definen lo que es bueno o malo, correcto o incorrecto, pero las ideologías controlan también nuestras creencias sobre el mundo, como en el caso de las ideologías religiosas o científicas (van Dijk, 2005: 295).

La definición adoptada por van Dijk remite a las funciones de la ideología; pero al hacerlo renuncia a explorar las características discursivas o textuales de los enunciados ideológicos. Renuncia a indagar si algún tipo de análisis puede delimitar la condición ideológica de los discursos al margen de que en ellos haya posicionamientos explícitos respecto de temas políticos, sociales, religiosos, económicos, etc.

Cuando van Dijk hace un análisis concreto de un discurso periodístico sí reconoce algunos procedimientos pues menciona, por ejemplo, el entimema; sin embargo no reconoce en el silogismo truncado una condición de la construcción ideológica. Van Dijk no contempla en absoluto, entre los discursos portadores de ideología, a los textos artísticos ni tampoco las propias tendencias estéticas con las que aquellos se vinculan. Dado que para nosotros los objetos de estudio interesantes son precisamente los textos artísticos - y en esta ocasión los audiovisuales narrativos-, debemos dotarnos de un aparato teórico que contemple el espesor polifónico y no pocas veces contradictorio de este tipo de producciones humanas a las que llamamos arte. Habremos pues de explorar otras perspectivas sobre la cuestión.

Para Terry Eagleton, teórico marxista británico, la ideología es un “ 'todo el mundo lo sabe', un saco de deslucidas máximas” (2006: 155). Sin embargo, esa escasa calidad teórica o racional, hecha de tópicos, "alberga la suficiente fuerza como para conducir al sujeto al asesinato o al martirio: con esta profundidad penetra en las raíces de una identidad unificada” (2006: 155). Es decir, lo ideológico resulta ser algo decisivo para entender el comportamiento de los individuos y, por eso, de los grupos sociales.

El filósofo y sociólogo alemán, J. Habermas, señala un origen para el fenómeno de las ideologías en relación con las transformaciones derivadas de los avances científicos de modo que "sustituyen a las legitimaciones tradicionales del dominio al presentarse con la pretensión 
de ciencia moderna y justificarse a partir de la crítica a las ideologías" — - y añade una reflexión muy pertinente-: "Las ideologías son coetáneas de la crítica ideológica. En este sentido no puede haber ideologías 'preburguesas'”(Habermas, 2009: 79).

Los profesores Douglas Hofstadter y Emmanuel Sander, expertos en psicología cognitiva en su trabajo acerca de cómo usamos las analogías en nuestro pensamiento y en nuestras actividades vitales_- , sin mencionar explícitamente la ideología, señalan cómo ciertas ideas son capaces, sin que seamos totalmente conscientes de ello, de encaminar y aun determinar por completo nuestras propias elaboraciones mentales y nuestras actitudes:

...las analogías emergen en nuestra mente sin que tengamos conciencia de ellas. Nos invaden de manera solapada y se adueñan del escenario. En segundo lugar las analogías nos coaccionan; fuerzan nuestros pensamientos a fluir en cierta dirección. [...] Moldean nuestra interpretación de las situaciones y determinan las conclusiones de nuestro razonamiento. La analogía no se contenta con colarse en la fiesta. Una vez ahí. Exige que, además se cambie la música (Hofstadter y Sander, 2018: 395).

El físico y epistemólogo argentino Mario Bunge se plantea las condiciones de los métodos científicos y aporta consideraciones que vemos oportunas para este caso, en tanto que las ideologías pueden ser calificadas de constructos: "En cuanto a los constructos, son total ficción: lo que es real es el proceso del cerebro que consiste en pensar sobre un objeto." (Bunge, 2008: 53). Añade Bunge otra distinción igualmente oportuna respecto de lo ideológico ya que la ideología tiende a establecer para los hechos sociales supuestas finalidades, entrando por ello en el terreno de lo confuso o dudoso.

Interpretar semánticamente un signo es asignarle por convención un hecho o un constructo, mientras que interpretar un hecho social es atribuirle hipotéticamente una finalidad. Además, mientras que el concepto semántico de interpretación puede aclarase, $[. .$.$] el otro se presta a confusión y, por lo tanto, a discusiones interminables$ sobre la naturaleza de lo social y el papel de las ciencias de la cultura (o del espíritu) (Bunge, 2009: 23).

Como vamos viendo, si la definición de ideología se enfrenta a algunas resistencias respecto de una deseable claridad y sencillez, el reconocimiento de sus funciones, sin embargo, surge con más rotundidad. Para complementar los postulados vistos hasta aquí e incorporar una perspectiva teórica más adecuada al objeto de estudio de la ideología, conviene introducir la noción de sujeto en toda su extensión (Lope, 2018b: 139-144).

La ideología es uno de los procesos discursivos de la subjetividad individual. Se desarrolla en la dialéctica entre lo deseable y lo detestable del imaginario y en la dialéctica entre el saber y el no saber de lo semio-cognitivo. Tales procesos están, en buena medida, determinados emocionalmente por el imaginario que es siempre individual y nunca colectivo. Los sentimientos de pertenencia a tribus, grupos, castas, partidos, refuerzan por la vía de la satisfacción emocional los postulados ideológicos. Lo racional se reduce al uso de cortocircuitos argumentales para llegar a conclusiones simplificadoras que perfilan un claro enemigo. En ese sentido, la ideología prefigura, en el límite más ciego, el odio y la muerte del otro, la aniquilación del que no comparte los mismos supuestos ideológicos. 
Así, lo ideológico es el espacio de los discursos no sujetos al rigor del método científico, discursos caracterizados por reutilizar una amalgama de elementos mitológicos o religiosos degradados y mezclados con argumentaciones simplificadoras de apariencia científica. El beneficio de la ideología para cada sujeto es el de poder escudarse tras ciertas fórmulas, compartidas con más gente, que evitan tener que hacerse demasiados cuestionamientos sobre la creciente complejidad de los problemas a los que se enfrenta la actual civilización. Civilización tecnológicamente avanzada pero moralmente desasistida, tras los prolongados procesos de deconstrucción de los grandes relatos mitólogos que permitieron la construcción de la civilización occidental.

Las personas se aferran a fórmulas ideológicas para no tener que hacerse preguntas incómodas, así adoptan los discursos justificativos que mejor se adaptan a su yo. Esto nos lleva a distinguir varios niveles ideológicos que son los que permiten este juego. Un nivel es el de la polarización política como mecanismo de control en las sociedades avanzadas. Esa polarización construye un universo simple de buenos y malos en el que cada cual puede convencerse, con unos pocos ideologemas, de que siempre sabe que está en el lado bueno de la confrontación.

Por encima de esa polarización —y para que ésta tenga lugar y resulte eficaz- es preciso que haya un nivel ideológico de tipo más general que va evolucionando con leyes no tan fáciles de entender. Esa especie de ideología ambiental no tiene aristas tan perceptibles y sus mecanismos productivos dependen mucho de cómo la gente va leyendo y reelaborando los múltiples discursos que recibe. Esta construcción ideológica que llamamos ambiental sí depende mucho de las experiencias estéticas proporcionadas por el arte, por la literatura o por las narraciones audiovisuales. Lo que se juega en este tipo de textos es la densidad y dignidad de lo simbólico o bien su deconstrucción más o menos feroz.

\subsection{Sobre la estética y sus implicaciones ideológicas}

En Occidente, la noción de estética es relativamente joven pues emerge en el siglo XVIII, si bien se venía fraguando desde el Renacimiento, a la vez que se crea la noción de Arte y de las Bellas Artes como algo muy diferente de las artesanías. Los medios de comunicación de la época: los libros, las revistas, los museos — que también fueron creados entonces - y las academias, sirvieron a la difusión de lo que se definió como experiencia estética. Esa experiencia estética, "un placer refinado" (Shiner, 2004: 24), era propuesta como un nuevo alimento para el alma en un momento en el que se procedía a desbancar, por su escasa racionalidad, a la religión del centro de la vida social y cultural de modo que la ritualidad sagrada se trasladó de las iglesias a los museos.

A partir del XVIII, los objetos considerados arte tenían valor por sí mismos y el artista alcanzaba una consideración especial por su sensibilidad, por su capacidad para ofrecer experiencias estéticas intensas a los sujetos que habían aprendido a valorarlas. Precisamente el establecimiento de valoraciones convertidas en discursos y sensaciones permite el engranaje entre estética e ideología. Terry Eagleton considera los vínculos entre estética e ideología como una red imprecisa pero influyente en el terreno cognitivo: "Lo ideológico-estético es esa región indeterminada, encallada en algún lugar entre lo empírico y lo teorético, en la que las abstracciones parecen resplandecer en su irreductible especificidad" (Eagleton, 2006: 155).

La irrupción de la estética constituyó un fenómeno de enorme trascendencia cultural precisamente por sus implicaciones ideológicas; tal irrupción es indisociable de la Ilustración pues mantiene una íntima relación con aquella aspiración intelectual de que las luces lograran penetrar hasta 
en los más profundos recovecos del ser humano y de los comportamientos sociales. El efecto ideológico de la Ilustración, esto es, su degradación popular, se convirtió en un cuestionamiento - no necesariamente reflexivo-, de todo cuanto hasta ese momento se había considerado sabiduría. Es también la reivindicación radical del individuo que decide pensar por su cuenta. Kant lo escribía así en 1784:

La Ilustración significa el abandono del hombre de una infancia mental de la que él mismo es culpable. Infancia es la incapacidad de usar la propia razón sin la guía de otra persona. Esta puericia es culpable cuando su causa no es la falta de inteligencia, sino la falta de decisión o de valor para pensar sin ayuda ajena. Sapere aude « ¡Atrévete a saber!» He aquí la divisa de la Ilustración (Kant, 2003: 1).

Esa es la base ideológica que ha sustentado tanto las revoluciones burguesas como las socialistas, tanto el liberalismo, como el nazismo y el comunismo. Nótese que esas frases de Kant tienen todo el sabor de las proclamas ideológicas. Esa fundamentación ideológica sigue siendo el sustrato de nuestras creencias contemporáneas, la ilusión de ser individuos que piensan por su cuenta y que, por tanto, son dueños de su futuro, de sus deseos y de sus gustos estéticos.

Recientemente han surgido posiciones muy críticas respecto de estas creencias optimistas por considerarlas insuficientemente justificadas y, lo que es más importante, contrarias al libre albedrío. En esa línea se manifiesta el filósofo británico Roger Scruton cuando reflexiona sobre la ilusión de la modernidad adoptada desde mediados del XIX:

Este fue el momento en que la falacia del movimiento del espíritu empezó a proliferar. En cada esfera se sostenía que debíamos mantenernos comprometidos con el espíritu de los tiempos, que adherirse a los viejos disfraces, los viejos valores o las viejas prácticas, ya fuese en política, en las relaciones sociales o en la expresión artística, era sencillamente comportarse como reaccionario (Scruton, 2010: 131).

Scruton pone de manifiesto las serias dudas que sectores amplios de las sociedades contemporáneas albergan respecto de la idea de progreso: "Reconozcamos al menos que el progreso en la esfera política es tan incierto como discutible. El cambio sucede, a veces de peor a mejor, a veces de mejor a peor" (Scruton, 2010: 131).

El filósofo vienés de querencias anarquistas, Paul Feyerabend, también se mostraba muy crítico con las influencias de la ciencia y de sus efectos ideológicos en la estética en general y en la representación artística de las vanguardias en particular, lo que le llevó a escribir que el "mundo colorista y polifacético de la conciencia habitual queda sustituido por una tosca esquematización en que no existen ni colores, ni olores, ni sentimientos, ni siquiera el curso temporal habitual; y esa caricatura es considerada ahora como la realidad" (Feyerabend, 2008: 151).

El crítico literario y profesor de origen belga, Paul de Man — que se dedicó además a la promoción de Derrida en Norteamérica—, aporta puntualizaciones muy a tener en cuenta sobre la función de la ideología en los ámbitos de la crítica y la creación, literaria en este caso, pero perfectamente extrapolables a la creación artística en general. "Los principios normativos del ambiente literario son culturales e ideológicos más que teóricos, orientados hacia la integridad de un yo social e histórico en lugar de hacia la coherencia impersonal que la teoría requiere" (de Man, 1990: 16). Es decir, la ideología del crítico o del académico que analiza y evalúa textos artísticos es una 
herramienta, una estrategia, de integración social para él mismo y, como tal estrategia social, suele alejarse del rigor y la coherencia que los métodos científicos requieren. Otro tanto se puede pensar del artista. Cuando de Man aborda de modo explícito el valor de lo estético resulta igualmente esclarecedor al considerarlo simultáneamente como síntoma y como engaño:

Las reacciones estéticas nunca pueden ser consideradas causas centrales sino sólo efectos secundarios triviales [...] El considerable interés que tiene para el historiador o para el filósofo crítico es sintomático y no sistemático: son [los juicios estéticos] filosóficamente significativos en tanto que su poder para engañar apunta a otras causas (de Man, 1990: 102).

Pasolini asumía con lucidez "que toda película, sutilmente, presenta algún tipo de vinculación con la ideología” (2018: 297) a la vez que establecía un mecanismo de diferenciación entre películas con más y con menos carga ideológica. Por ejemplo, consideraba cintas suyas como Los cuentos de Canterbury (I racconti di Canterbury, 1972) o El Decamerón (Il Decameron, 1971) mucho menos ideológicas al "mostrar personajes y situaciones que son completamente reales" (Pasolini, 2018: 297). Así planteaba un intelectual y creador de formación marxista ese juego de oposiciones por el cual la representación artística de situaciones reales sería una forma de eludir, en parte, la ideología.

El profesor norteamericano W. J. T. Mitchell, en sus más recientes reflexiones acerca de los estudios sobre la cultura visual, denuncia como perturbadas las actuales discusiones sobre el tema precisamente por aplicar de forma poco rigurosa cierta "retórica de la innovación y la modernización” (Mitchell, 2017: 73) un retórica que tiende a considerar a las imágenes como "proyecciones de la ideología, como tecnologías de dominación que ofrecen resistencia a la perspicaz crítica” (Mitchell, 2017: 73). Podemos nosotros deducir que los actuales métodos de análisis de las imágenes, y por extensión de los textos artísticos, están bajo la influencia de postulados ideológicos que vienen disfrazados de innovación sin tener en cuenta que la innovación tecnológica no significa una innovación teórico-metodológica en absoluto, al menos no de una forma tan mecánica como suele proclamarse.

La estética ha conocido cambios muy espectaculares, sobre todo, a partir de los experimentos deconstructivos y rupturistas a finales del XIX, pronto consagrados por las vanguardias de principios del XX. El triunfo de esas primeras vanguardias — dadaísmo, surrealismo y futurismo - ha consistido en que, a pesar de presentarse como antiartísticas y antisistema, han sido integradas dentro de la estética cotidiana; una labor en la que los medios de comunicación como el cine, la televisión, internet, la publicidad, la música (pop, rock, rap, electrónica), el diseño industrial, la arquitectura, el urbanismo, el software, la moda, etc. son decisivos.

Tales fenómenos comunicativos van construyendo nuestra cultura visual y audiovisual. Una cultura que necesita estar demostrando constantemente que es capaz de hacer cosas nuevas, que se vean originales, demostrando que puede cambiar formas, colores, ritmos, aunque esos cambios no tengan más sentido que el de alimentar los propios procesos de estetización de la vida cotidiana. El paradigma de estos procesos es el de la moda.

\subsection{La ideología en la narración audiovisual}

Para centrarnos en los contenidos ideológicos del audiovisual narrativo debemos echar mano de algunos aportes más. Así, incorporamos como opción teórico-metodológica útil para el 
propósito de este trabajo, el análisis textual junto con el concepto de sentido tutor promovido por Barthes en $S / Z$ (2004) y desarrollado por González Requena en el análisis sobre el cine de Eisenstein y sus inscripciones ideológicas manifiestas (1992: 7-43).

Buscar la ideología en un texto audiovisual debe comenzar por localizar su sentido tutor y ello lo encontramos en esos discursos que, de modo explícito, proclaman lo que pretende decir la obra en cuestión. El primer elemento de construcción del sentido tutor está en el título y en las frases promocionales y, ya dentro del propio texto audiovisual, hay que ir detectando los elementos discursivos que tratan de ser justificativos del propio conjunto textual. A poco que la obra en cuestión sea artísticamente relevante, iremos comprobando que ese sentido tutor es insuficiente para dar cuenta de la experiencia subjetiva que desencadena.

El efecto ideológico se produce cuando el lector espectador trata de encerrar esa experiencia en fórmulas que considera aceptables por los demás. Así, o bien adopta el discurso tutor como propio o bien lo matiza para adaptarlo a posiciones ideológicas con las que se identifica y que prefiere no cuestionar. Ocurre que ciertas obras evitan deliberadamente construir un sentido tutor para que el espectador acceda a la misma desprovisto de toda guía. Algunas series solo llevan las etiquetas genéricas de "policíaca", "drama" y una breve descripción a modo de palabras clave como "FBI" y "psicología del asesinato", por ejemplo. Así de escueto queda el sentido tutor: hay policías, psicología y asesinos.

Lo específico de una narración, sea audiovisual, literaria, teatral, oral, es que contiene conflictos y que los personajes están involucrados en la evolución de esos conflictos. Esa evolución que hace que unas situaciones se transformen en otras nuevas está determinada por las relaciones de causa-efecto que los autores han seleccionado para pasar de una situación inicial a una situación final —o bien última, en caso de que el relato no se cierre-, pasando por un número más o menos amplio de episodios intermedios. Esa selección de relaciones causales no es siempre y por completo consciente, pues está determinada por el deseo del sujeto en el proceso de escritura. Ese deseo está, de hecho, influido por ideologemas que operan como anclajes de sentido para el imaginario individual.

La selección de los encadenamientos causales no es inocente; pero tampoco es del todo voluntaria, e implica la prexistencia de ciertas condiciones de posibilidad para un determinado universo narrativo en el que pasan unas cosas pero no suceden otras. Esa lógica que hilvana los aconteceres narrativos es, en efecto, ideología. Por ejemplo, en la causalidad organizadora del universo de ficción puede estar la explicación de la imposibilidad del héroe, lo cual tiene efectos argumentativos en algunos espectadores. Así sería el caso del encumbramiento de la víctima a la condición de personaje justiciero, deformando la propia noción de justicia al degradarla bajo la forma de la venganza personal.

Otro ámbito de la comunicación contemporánea donde se procede a seleccionar unas relaciones causales en detrimento de otras es el de la información sobre la realidad (periodismo, reportajes, documentales y narraciones audiovisuales) en cualquiera de sus vías y soportes. En este caso, una selección causal determinada puede recubrirse de supuestas buenas intenciones a favor de ciertas causas valoradas ideológicamente como positivas por las élites de las administraciones y de las grandes empresas que establecen lo que es deseable y lo que es detestable.

A su vez, los medios de comunicación se encargan de difundir y consolidar nuevos términos, 
nuevas palabras que son indicadores ideológicos, o ideologemas cuya presencia sirve para identificar la pertenencia del discurso a una determinada corriente. George Orwell calificó este procedimiento en 1984 como Newspeak, neo-lengua (Orwell, 1983: 48-50).

La publicidad y la propaganda son también espacios cómodos para la carga ideológica. Aquí se puede prescindir de establecer lógicas causales racionales y coherentes, pues se suele apelar directamente al imaginario individual para establecer — de una forma bastante primitiva - lo que es deseable y lo que es detestable. El núcleo de los rudimentos argumentativos suele ser el miedo.

En una narración audiovisual pueden aparecer perfectamente combinadas estas tres formas de construcción ideológica y, de forma muy acentuada, si se trata de reportajes y documentales audiovisuales, discursos estos que se han convertido en los vehículos contemporáneos más propensos a la manipulación, la tergiversación y el escamoteo de la verdad objetiva, es decir, a la construcción de ideologías. Como recuerda Eagleton (2007: 61) a propósito de Brecht y la retórica, "Los enunciados no 'representan' referentes sino prácticas, incluyendo otros enunciados: 'gestos, imitaciones, tonos de voz' ". La eficacia manipuladora deriva de que, con la excusa de la información, se despliegan prácticas que esconden el acceso a lo real, al saber de lo real, construyendo eso que se conoce como falsa conciencia.

$\mathrm{Al}$ analizar las estructuras narrativas y las funciones de los personajes en la narración audiovisual seriada contemporánea surge un rasgo característico: la tarea mayoritaria que asumen los personajes protagonistas es una que permite acercar al espectador a lo real de la violencia, la muerte, lo absurdo, la corrupción, la cobardía, la codicia, el sexo, la perversión, el sinsentido, la locura. Junto a la explotación de la pulsión escópica — según la cual al espectador se le hace creer de igual manera que el realismo es poder ver en detalle un cuerpo en descomposición, o que la única verdad incuestionable es la del horror y el sinsentido de lo real一, se despliegan estrategias de incertidumbre narrativa y de suspense (Lope, 2017).

La tarea del detective policial y personajes similares incluye ese contacto brutal con el espanto de lo inhumano. Estos personajes suelen experimentar de forma más o menos disimulada cierto goce en ese encuentro con las huellas del crimen. El horror es el espectáculo, en combinación con una violencia estetizada a cámara lenta y en alta definición, una consternación que se extiende en el trauma de los allegados de las víctimas — si hay dolor sincero, lo que tampoco sucede siempre pues, en demasiadas ocasiones, las cosas no son lo que parecen-. Además, el investigador policial está sometido a un rígido sistema de protocolos de actuación que lo convierten en pieza de un engranaje que funciona de forma impersonal y que cada vez tiene mayor capacidad para controlarnos a todos.

La libertad individual y la dignidad del ser humano son cosas que ya no pertenecen ni a esta contemporaneidad acelerada ni, mucho menos, al futuro previsible. A cambio, ese sistema de control ofrece en las redes sociales el espejismo de un empoderamiento que no llega nunca, pues no van más allá de proporcionar experiencias narcisistas en las que cada cual pueda acomodarse. Este sería el ideologema básico que recorre los textos audiovisuales contemporáneos.

Tratemos de resumir el conjunto de síntomas: la única verdad estable es el horror, no somos libres ni tal vez merezcamos serlo, no vale la pena ser héroe, pues se sufre demasiado y no hay recompensa sino traición; averiguar la verdad del comportamiento humano es desagradable; 
traer hijos al mundo puede ser una irresponsabilidad; nada tiene sentido, pero tenemos que vivir lo mejor que podamos y si para ello hay que ser cínico, incoherente o traidor, pues tampoco es tan grave; la humanidad es culpable de graves atrocidades, pero yo que veo cómo es la humanidad y, en el fondo, la desprecio, soy mejor. El caso es que en esto también hay unas pocas excepciones.

Como se puede deducir, la ideología nihilista está anidando en la mayor parte de la ficción audiovisual con elevados índices de audiencia. Su estética inherente tiene grandes dosis de incertidumbre, bastantes juegos manieristas, tanto autorreferenciales como de apariencias desengañadas, excitación de la pulsión escópica, deconstrucción de conexiones significantes. En tanto que la estética de lo visual se puede pensar como un conjunto de códigos y de estrategias de gestión de la mirada del espectador en la procura del goce — no necesariamente por medio de la belleza-, la ideología queda engranada como discurso capaz de otorgar alguna justificación incluso al sinsentido de algunas propuestas artísticas. El discurso ideológico, pegado al estético, resultará muy fragmentario, no poco contradictorio, apelará a innumerables referentes históricos, sociales, políticos para, como dice Bunge, atribuir finalidades.

\subsection{La estética de los créditos}

En la realización de audiovisuales, cuando llega el momento de hacer los créditos, hay una cuestión que los editores siempre tienen en cuenta — aparte del tamaño, la tipografía, el color, los fondos, el sonido o la música—; se trata de los tiempos de presencia en pantalla de la información escrita y, en el caso de que haya movimientos o disolvencias, las duraciones de estos efectos. En general, se trata de alcanzar un compromiso razonable entre un tiempo mínimo para que el espectador tenga tiempo de leer lo esencial y que a la vez no sienta estar perdiendo el tiempo con información que, en ese momento, no le interesa en absoluto. Hay otro compromiso a alcanzar en los títulos entre la relevancia de la información visual y la relevancia de la información escrita: se recomienda una planificación que tenga en cuenta zonas del encuadre sin información visual importante para que éstas puedan ser ocupadas por los letreros.

Desde que la digitalización se ha impuesto tanto en los procesos de creación como en los del visionado, se percibe un deliberado acortamiento del tiempo de presencia de los textos escritos pues se considera que el espectador puede poner en pausa el vídeo y así leer como quiera cada plano o cada fotograma. Resulta que esa preocupación por el tiempo del espectador está en los más lejanos orígenes del espectáculo cinematográfico como nos recuerda la viñeta que incluye Rick Altman en su libro Silent Film Sound (2004: 180).

Lo primero a tener en cuenta es que en la pantalla convive la información escrita, las palabras, con las imágenes de las historias. Ambos, letra y fotografía, son elementos visuales. Los referentes de las palabras suelen ser personas que no aparecen dentro de las historias, salvo cuando esas palabras nombran a los actores. Las imágenes, sí son fotográficas, son huellas directas, más o menos retocadas o post-producidas, de lo real que hubo en algún momento ante la óptica de la cámara. Desde los orígenes del espectáculo cinematográfico, la letra consiguió tener un sitio en la pantalla.

Coincidimos por ello con Iván Bort (2012: 462) —autor de una interesante clasificación de los tipos de secuencias de créditos-, cuando defiende que es un error considerar a la actual ficción serializada y a la ficción cinematográfica "como dispares y disímiles" pues trabajan con las mismas variables de la estructuración narrativa y también con recursos escriturales perfectamente 


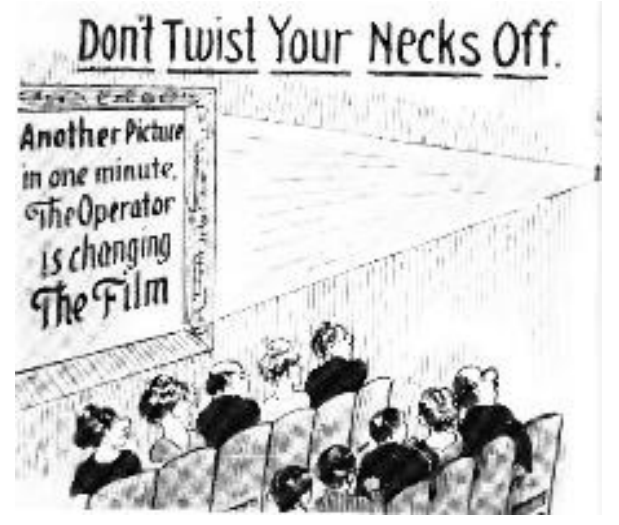

Figura 1. Don't Twist Your Necks Off. Fuente: Altman, Rick (2004). Silent Film Sound, p. 180.

intercambiables. Sin embargo, Bort no extrae todas las consecuencias de esto último, pues no tiene en cuenta las diferencias entre los modos de representación cinematográfica que también afectan a las series y, por tanto, a los créditos. Por ejemplo, no es lo mismo una escritura audiovisual clasicista que una más escorada hacia el manierismo y el postclasicismo (González Requena, 2006).

Los rasgos narrativos y escriturales más frecuentes detectados en las series recientes son los de la incertidumbre, el suspense y la pulsión escópica (Lope, 2017) como corresponde a escrituras audiovisuales postclásicas con fuertes querencias manieristas. Ahora bien, se trata de analizar si esos ingredientes aparecen y en qué modo en los créditos de las series El puente (cuarta temporada) y Mindhunter (primera temporada).

\section{Metodología}

El método de trabajo a emplear debe servir para buscar en el texto audiovisual un conjunto de rasgos señalados en la fundamentación teórico-metodológica anterior. Ya se ha mencionado la obra de Barthes $S / Z$ como fuente del concepto sentido tutor y ahora debemos recuperarla también como una de las bases metodológicas a seguir en este caso. Un procedimiento en la estela del que inaugurara Sigmund Freud (2013) cuando analizaba de forma minuciosa la escultura el Moisés de Miguel Ángel.

En este estudio, la metodología seguida es la del análisis mediante un deletreamiento minucioso de los elementos visibles dentro del encuadre. El proceso de trabajo comienza con el reconocimiento de las formas y de los fondos presentes en los planos evitando la interpretación prematura. Ese intento de reconocimiento puede chocar con niveles de incertidumbre semiótica más o menos elevados y, del mismo modo, puede mostrar más cercanía o lejanía bien a lo narrativo o bien a lo descriptivo.

Después, se exploran los vínculos asociativos entre los motivos hallados y el universo narrativo de la serie. Esto supone la interrogación acerca de si los motivos fotografiados están anclados en el mundo físico donde tienen lugar las secuencias de las historias representadas. Seguidamente procedemos a interrogarnos acerca de si, en ciertos casos, emergen en las imágenes funciones de carácter metafórico o alegórico y, a la vez, nos planteamos la detección de otros posibles juegos semánticos en torno a las implicaciones de sentido o de sinsentido. Finalmente, procedemos a extraer de los análisis anteriores los rasgos que permiten la identificación de patrones en relación con los modos de representación, con la estética y con la ideología. 


\section{Resultados y discusión}

Recordemos que en ambos casos la secuencia de créditos tiene lugar después de haber mostrado al espectador algún suceso impactante, eso que en la terminilogía de los seriéfilos se conoce con la discutible expresión de cold open. Baste fijarnos en el primer capítulo de la temporada cuatro de El Puente ${ }^{3}$ y en el primero de la primera temporada de Mindhunter ${ }^{4}$. En el primer caso vemos a la protagonista, la detective sueca Saga, encarcelada; y acto seguido una lapidación de una mujer bajo el puente que da título a la serie. Esas dos secuencias duran casi 4 minutos. En el segundo caso asistimos a una secuencia que dura algo más de cinco minutos en la que un perturbado tiene a cinco rehenes, llega un agente del FBI, Holden Ford, que se hace cargo de la situación intentando calmar al secuestrador; pero éste se vuela literalmente la cabeza con una escopeta de cañones recortados.

El ingrediente más poderoso que exhiben los dos comienzos es la excitación de la pulsión escópica del espectador junto con notables dosis de incertidumbre acerca del sentido tanto de la lapidación como del suicidio. Ambos acontecimientos sangrientos suceden de noche y cargan las expectativas del espectador de inquietud, horror, oscuridad e indeterminación narrativa, una mezcla que resulta bastante incandescente. Es decir, ejercen una influencia sensorial, no cognitiva, al modo en el que lo hace el efecto Kuleshov (Lope, 2018 a) pues se transfieren esas sensaciones a las secuencias siguientes que son las de los créditos.

\subsection{El caso de El puente}

Veamos una selección de 22 fotogramas suficientemente representativos de los 18 planos que se ven durante los aproximadamente 60 segundos que duran los créditos y que nos informan, al inicio, de los nombres de las empresas productoras y, al final, del título de la serie.
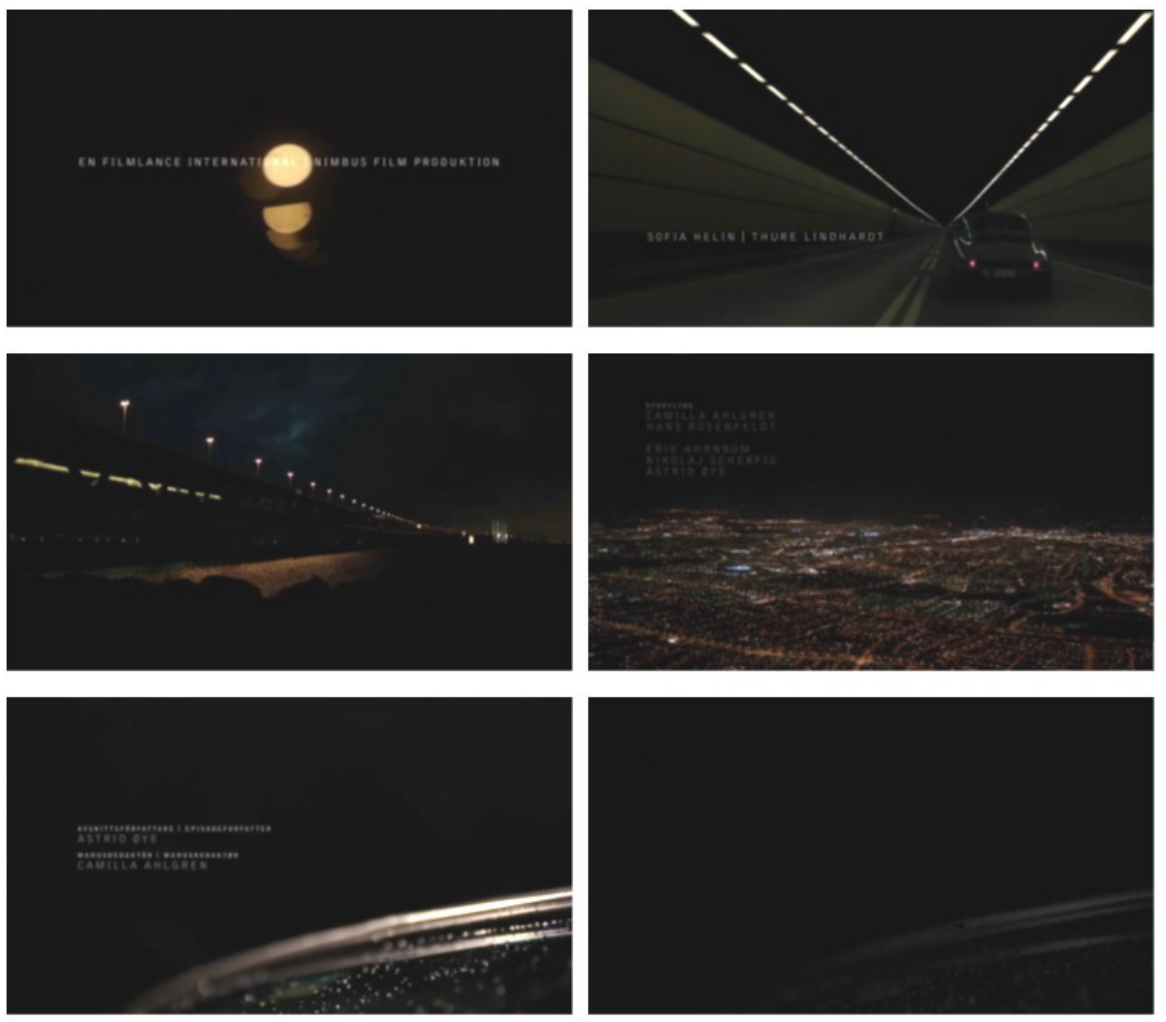

${ }^{3}$ Bron (El puente) (2011-2018). Episode \#4.1. (ficha técnica y artística). Disponible en:

${ }^{4}$ Mindhunter. Episode \#1.1 (ficha técnica y artística). Disponible en: https:/ /www.imdb.com/title/ tt5534132/?ref_=adv_li_tt 
MHCJ nº 9 (2) | Año 2018 - Artículo n 14 (129) - Páginas 379 a 400 - mhjournal.org
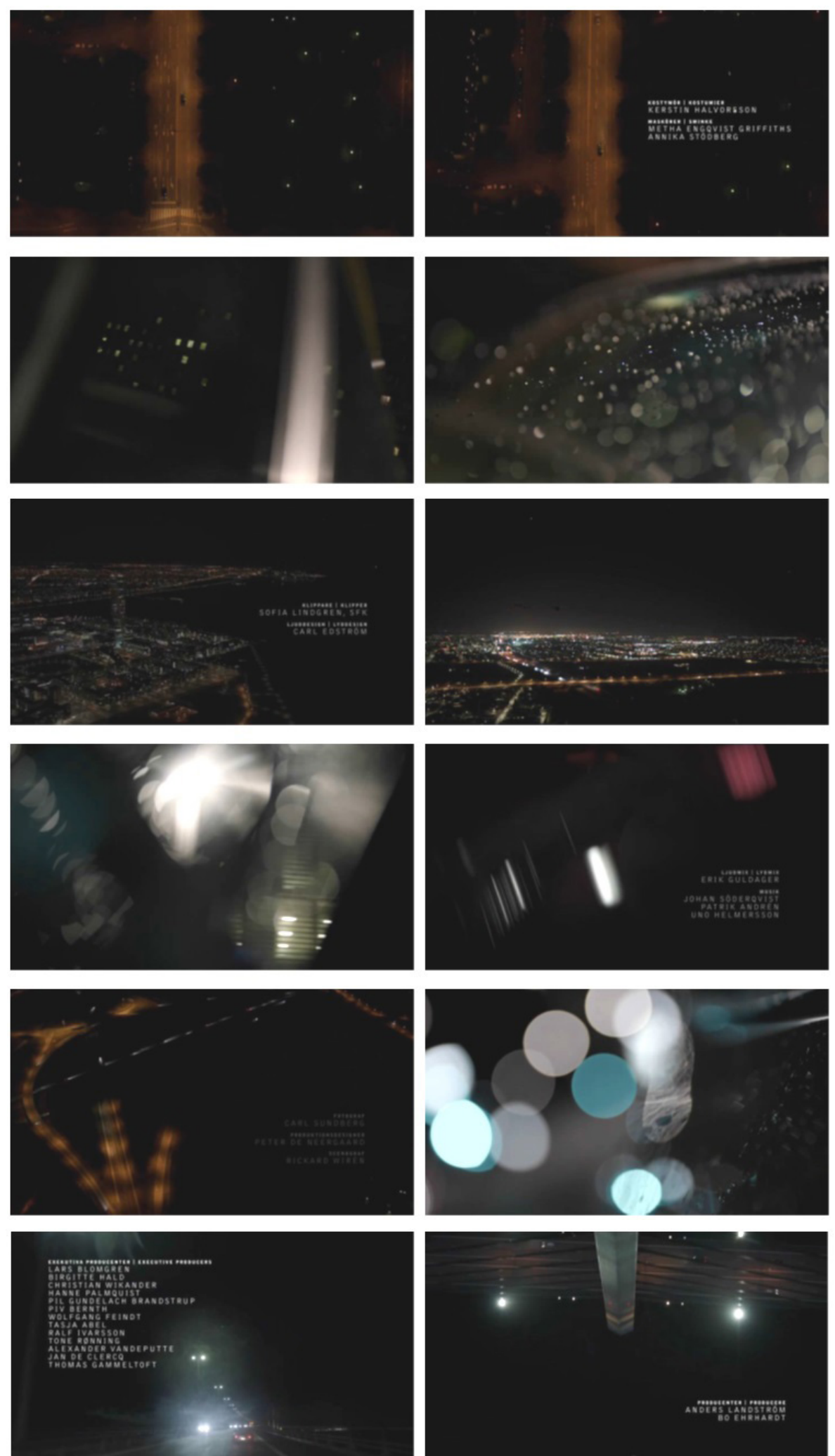

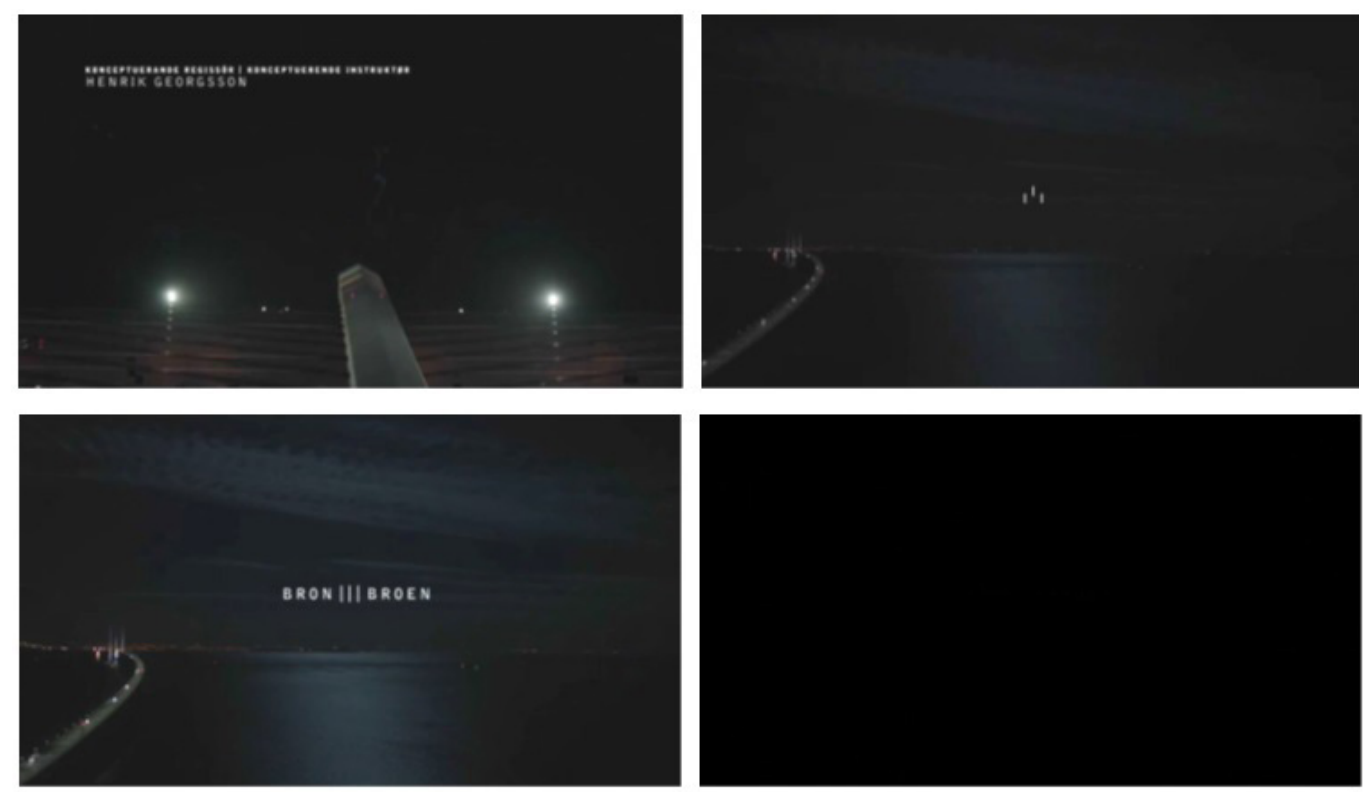

Figura 2. Selección de fotogramas de los créditos de El Puente. Fuente: vídeo de la serie en Netflix.

El tiempo de presencia de las palabras Bron (sueco) y Broen (danés) es de 5 segundos incluyendo su emergencia inicial y su disolución final en negro. El resto de los textos no sobrepasa los dos segundos de presencia. Esos textos han ido apareciendo escritos sobre imágenes nocturnas en las que la oscuridad se apodera de la composición y algunos destellos, a veces enfocados, otras desenfocados, proclaman el origen artificial de la luz. Todo se mueve suavemente, con desplazamiento de cámara y con movimiento interno. En el último plano —el formato es de 16:9— coloca el puente a la izquierda y deja mucho aire en la derecha para escribir el título en el centro, título que en este caso parece una redundancia informativa pues nombra lo que se ve. De ese modo, el espectador avezado intuye que no se trata de una ingenua decisión, sino la intención de provocar una más amplia y difusa significación para la noción de puente.

Los letreros de los créditos emergen sobre tales imágenes. La información de las mismas queda limitada a algunos referentes genéricos: el túnel oscuro, los destellos luminosos - a distancia imprecisa debido al desenfoque- o las vistas aéreas sobre el puente en la noche que enfatizan un vacío apenas mitigado por una vía de luz suspendida, como flotando, en medio de la nada. Esa vista sobre el puente desde arriba evoca una frágil comunicación entre dos partes y también aboca al vértigo.

Como no aparecen rostros humanos en los créditos, en lugar de producirse — vía efecto Kuleshov- la transferencia emocional desde las dos secuencias iniciales, la secuencia de créditos extiende, como construyendo un puente, esas mismas sensaciones inquietantes a la siguiente secuencia. Y así, al abrir de negro, el rostro del policía danés recibe toda la penosa carga sensorial, elaborada en las primeras dos secuencias y acentuada en la de créditos. 

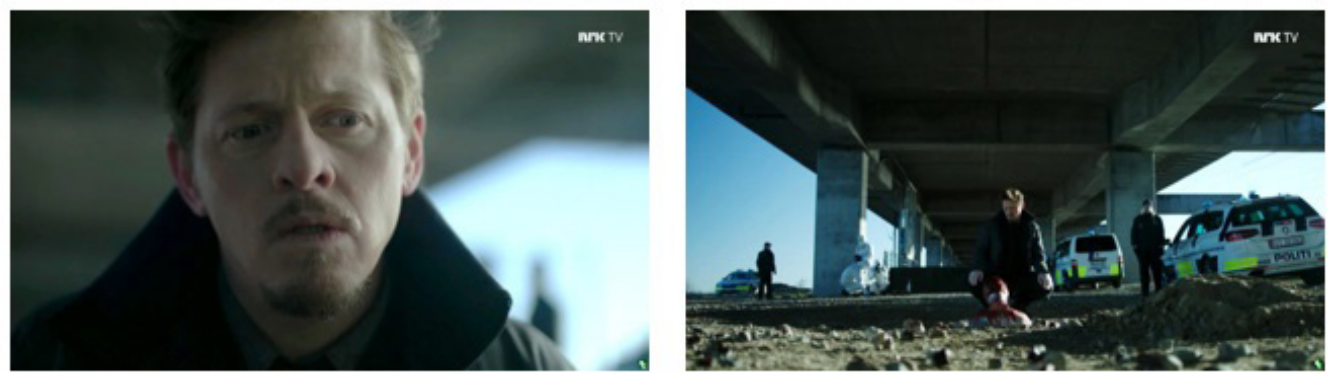

Figura 3. El detective frente al cadáver, bajo el puente. Fuente: vídeo de la serie El Puente.

Eso que ahora ve el policía es el resultado de lo que el espectador ya había visto antes: la lapidación bajo el puente.

\subsection{El caso de Mindhunter}

Una máquina analógica de audio es puesta en marcha meticulosamente. Es una secuencia de acciones que la digitalización ha simplificado. Por eso podemos sospechar que estamos en un tiempo pasado, años 70. Los créditos de cada capítulo se escriben mientras una mano derecha enhebra una cinta magnetofónica abierta de la marca TDK en la grabadora. Cuando la cinta está colocada, la mano derecha acciona la rueda de puesta en marcha de la grabación mientras se encienden dos luces rojas asociadas a la abreviatura Rec, también en rojo. Luego, la mano derecha ajusta el volumen en una rueda. La grabadora está en marcha, las bobinas con la cinta giran. La mano derecha cierra una tapa de plástico transparente sobre las bobinas y las cabezas de grabación. La mano izquierda conecta el micrófono. Luego orienta el micrófono bajándolo levemente. Todo esto se ve en un formato de 2.21:1.

El título Mindhunter aparece escrito en letras blancas sobre un combinación de la imagen de las bobinas girando y una superficie oscura y líquida. Finalmente, tras los nombres de los productores, aparece el nombre del director a la izquierda mientras a la derecha se ve, con muy poca profundidad de campo, la parte delantera con la rejilla del micro. Funde a negro y continua el capítulo que había comenzado unos tres minutos antes. Esta secuencia de créditos comienza en 1:39 y termina en 3:16.
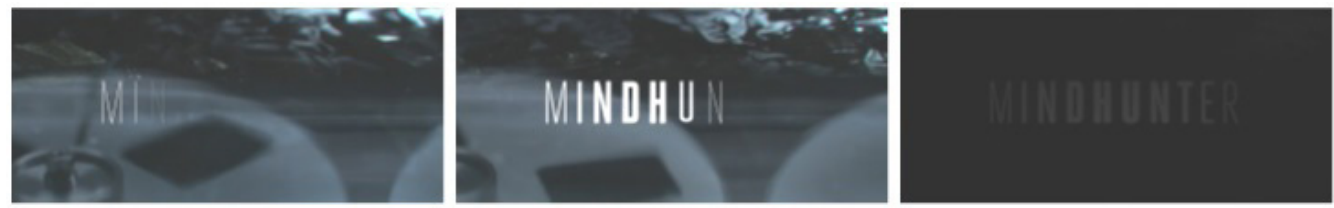

Figura 4. Emergencia y desvanecimiento del título Mindhunter al final de la secuencia de créditos.

Fuente: vídeo de la serie Mindhunter.

El título, desde que empieza escribirse letra a letra hasta que desvanece en negro, permanece durante siete segundos, un lapso comparativamente mayor a la duración de, por ejemplo, los actores de la serie cuyo nombre permanece unos dos segundos. Lo notable de estos créditos, con una duración de 97 segundos, consiste en la inserción fugaz de una colección de 24 imágenes que provienen de escenarios del crimen donde 
se ven detalles de cadáveres con señales de haber sufrido agresiones realizadas con violencia extrema — un trabajo del artista visual de origen polaco Darek Zabrocki ${ }^{5}$.

Como se observa, los momentos de irrupción no presentan un patrón o un ritmo reconocible. A veces, entre la aparición de una imagen y la de la siguiente hay tres segundos (en seis ocasiones, siendo el lapso de tiempo más repetido), otras veces sólo hay uno o dos segundos y, en alguna ocasión, incluso hay ocho segundos. La sucesión de las diferencias queda ordenada así: 2, 3, 5, 3, 7, 1, 4, 1, 2, 4, 4, 2, 5, 3, 5, 5, 1, 3, $8,6,3,1$ y 3 . Podemos, por ello, considerar que se trata de una escritura audiovisual que refleja, por un lado, el caos de la pulsión desatada del psicópata y, por otro, lo imprevisible de su emergencia.

Cada emergencia cuenta apenas con tres o cuatro fotogramas, irrupciones tan fugaces que hacen imposible obtener suficiente información de su contenido si no se emplea la pausa, si no detenemos el flujo audiovisual para contemplar el horror con un espeluznante grado de detalle. No podemos ignorar un significativo antecedente en una película de David Fincher — quien, por cierto, tiene una posición muy destacada tanto en la producción como en la dirección ya que dirige cuatro de los capítulos de la primera temporada-. 18 años antes, en El club de la lucha (Fight Club, 1999), Fincher ya había prestado atención a esta práctica de incluir unos pocos fotogramas casi imperceptibles dentro de una proyección cinematográfica.
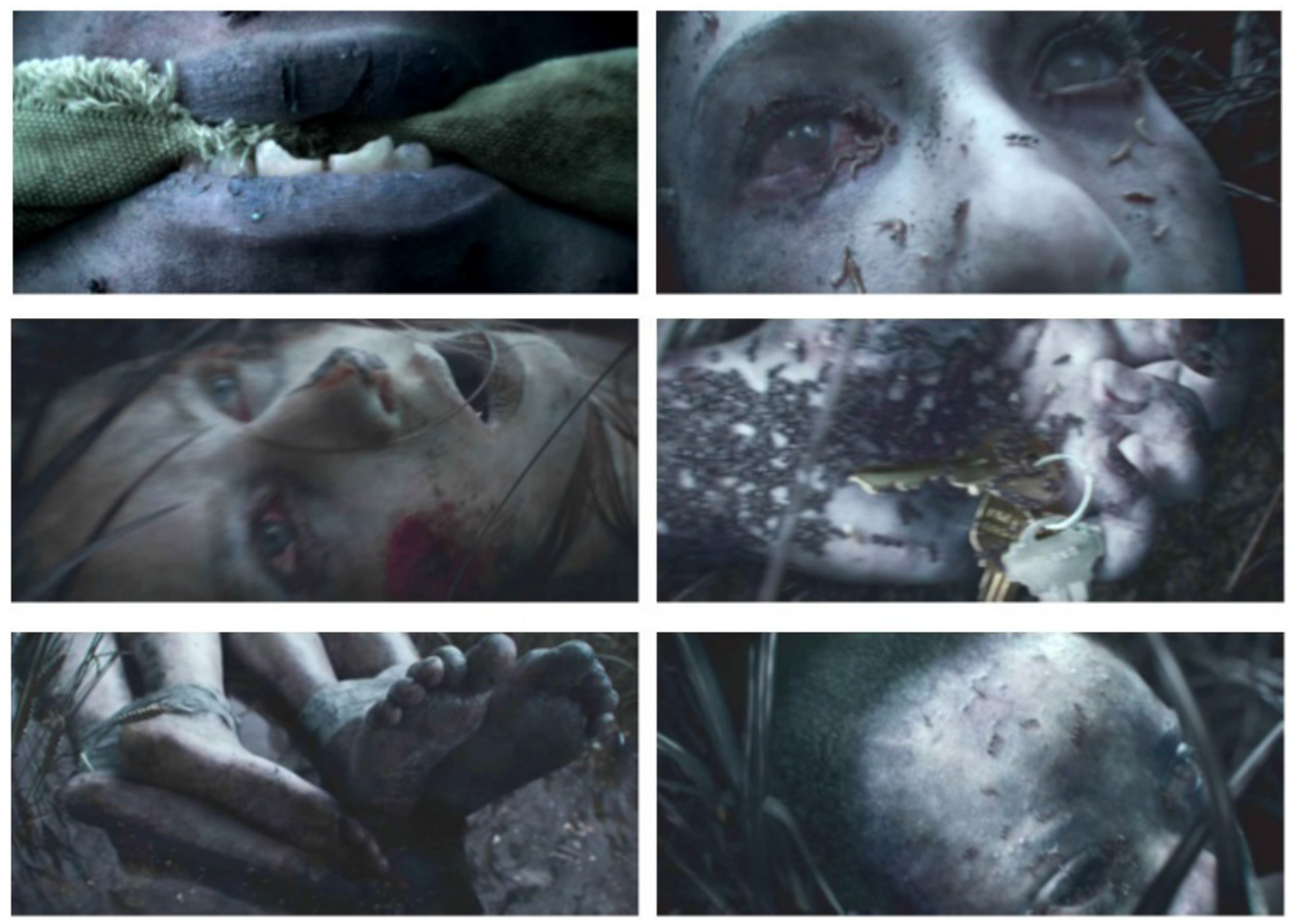

Figura 5. Seis de los fotogramas de cadáveres. Fuente: vídeo de la serie Mindhunter.

${ }^{5}$ Mindhunter, (2017, Netflix). Aquí es posible leer cómo Darek Zabrocki afrontó el encargo de David Fincher: https:/ / www.darekaabrocki.com/ - / mindhunter/ 

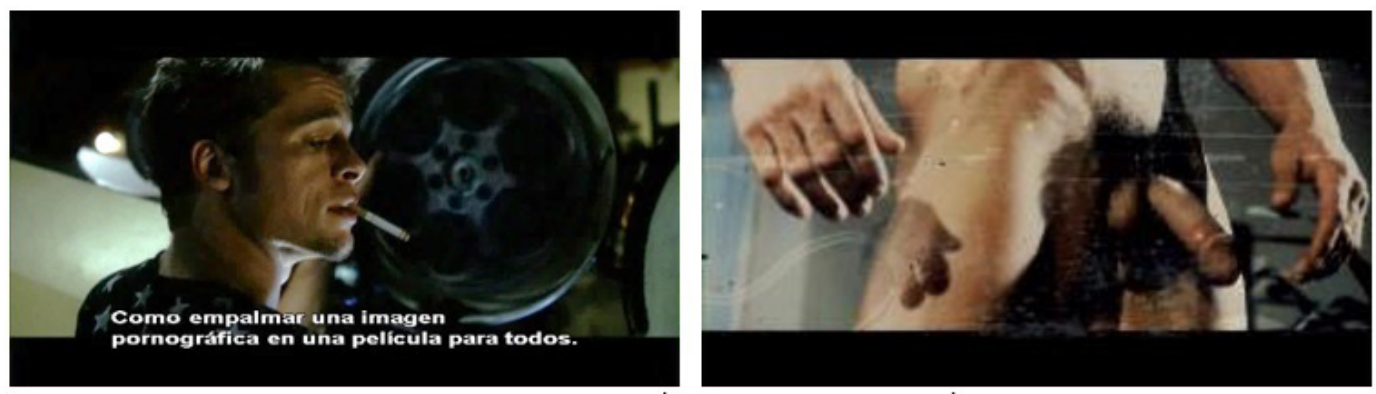

Figura 6. Dos fotogramas que aluden a la inserción fugaz de pornografía en un film. Fuente: El club de la lucha de David Fincher.

En aquel caso, el psicópata Tyler Durden, que trabaja como proyeccionista en una sala de cine, se dedica a incluir algunos fotogramas de cintas pornográficas en las sesiones para todos los públicos. Así, la perversa actividad de uno de los perturbados protagonistas de la película es en los créditos de esta serie un rasgo asumido como propio por la enunciación. Ningún indicio permite suponer que hay un autor diferente de aquellos que en los propios créditos aparecen como responsables máximos de su creación.

\subsection{Discusión}

Los créditos analizados tratan de eludir una identificación ideológica de las que suelen polarizar a la opinión pública en las democracias occidentales entre derecha e izquierda, entre propuestas conservadoras y progresistas; una polarización a base de simplificaciones ideológicas contrapuestas, o aparentemente contrapuestas. Eso no quiere decir que esos asuntos no estén representados en los capítulos por medio de personajes que manifiestan ese tipo de posicionamientos, pero en los créditos se evita toda presencia de personajes identificados.

Hay notables diferencias en el plano estético entre los créditos de Elpuente y los de Mindhunter. En el caso de la serie sueco-danesa los créditos trabajan sobre una representación de la fluidez a partir de una dirección de fotografía que enfatiza el fondo negro para destellos luminosos enfocados y desenfocados. La cantidad de información visual resulta ser bastante baja. Los créditos de Mindhunter trabajan en la ruptura del flujo visual con la inserción de fotogramas de cadáveres abandonados vistos con gran detalle. La limpieza inmaculada de la grabadora de audio analógica es el contrapunto de los cuerpos en descomposición, como si el caos de lo real y la pulsión homicida amenazaran con la disolución de todo orden.

Dos cosas comparten los créditos de ambas series:

a) El uso explícito de dos medios de comunicación como el puente y la grabadora.

b) El cese de toda comunicación, pues eso representa tanto el fondo negro como los cadáveres.

\section{Conclusiones}

A la vista de los resultados, los créditos reivindican una estética que trata de manejar fuerzas muy contradictorias. De esa dialéctica se deriva un destilado ideológico que se visualiza del siguiente modo: tanto las luces como el orden son frágiles, el caos y el horror son una amenaza más cercana de lo que suele creerse. Se confirma así la hipótesis de este trabajo: la estetización de la oscuridad, de la falta de horizonte y del sinsentido contribuye a que estos aspectos se hagan siniestramente familiares y se combinen como un difuso constructo ideológico que posteriormente puede ser reutilizado en constructos más específicos. Eso no implica que haya 
una intencionalidad consciente en los creadores respecto de sus implicaciones ideológicas. Bien puede ser al revés y que sea su propio deseo inconsciente el que se encuentre cómodo en ellas.

La primacía de la estética en los créditos es en sí misma una proclama ideológica: procurar que el discurso de los créditos no tenga un sentido unívoco sino más bien abrir un abanico de alusiones, de posibles conexiones intertextuales, de asociaciones tan libres como determinadas por las experiencias subjetivas de cada espectador. En estos créditos hay una dirección de fotografía muy cuidada que aborda directamente las tensiones presentes en la experiencia subjetiva de los individuos dentro de las actuales sociedades, tecnológicamente avanzadas y también enfrentadas a unos horizontes oscuros e inquietantes. La estética de este tipo de visualizaciones tiene una dimensión ideológica que incide en la relativización significante, en la deconstrucción gozosa de los significados y de los valores estables. Hacen ver que no hay referentes para la verdad salvo el horror, considerado como la única certeza.

Los créditos en estos dos casos tratan de no establecer un sentido tutor para el conjunto de la serie respectiva pero no pueden dejar de construir una sensorialidad, un ambiente, entre inquietante y siniestro, enfermizo incluso. Este tipo de formulaciones por la vía estética consagra ciertas presunciones, simplificaciones que son como un armazón sensorial de cualquier concreción ideológica: que la única verdad es el horror, lo único seguro es la muerte, el miedo, el dolor, la falta de horizonte, el fondo oscuro contra el que escribir las palabras que nos informan del título y de los responsables de la experiencia narrativa a la que se nos invita. Tal experiencia comienza, no lo olvidemos, antes de que se nos ofrezca su título, que es como decir: la palabra escrita, puede esperar.

\section{Bibliografía}

Altman, Rick (2004). Silent Film Sound. New York: Columbia University Press.

Barthes, Roland, (2004). S/Z. Buenos Aires: Siglo XXI Editores.

Bort, Iván (2012). Nuevos paradigmas en los telones del relato audiovisual contemporáneo: particulas narrativas de apertura y cierre en las series de televisión dramáticas norteamericanas. Tesis doctoral. Castellón: Universitat Jaume I. Disponble en: http://hdl.handle. net $/ 10803 / 81927$

Bunge, Mario (2008). Semántica I. Sentido y referencia. Barcelona: Gedisa. - (2009). Semántica II. Interpretación y verdad. Barcelona: Gedisa.

Cortés, Alfonso (2014). Ideología en los contenidos mediáticos: Estudio sobre las series televisivas en España desde la perspectiva de la Cultura de Paz. MHCJ (5), 35-52. Recuperado de https://goo.gl/VpkTs6

de Man, Paul (1990). La resistencia a la teoría. Madrid: Visor.

Donstrup Mayte (2017). House of Cards: ideología y poder en la serie de Netflix. RUTA Comunicación (8), 45-63. Barcelona: Universidad Autónoma de Barcelona. 
Disponible en: https://goo.gl/ecjLbd

Eagleton, Terry (2006). La estética como ideología. Madrid: Editorial Trotta. - (2007). Brecht y la retórica. Minerva. Revista del círculo de bellas artes (6), 60-62. Madrid: Círculo de Bellas Artes. Disponible en: https://goo.gl/1dS4ni

Feyerabend, Paul (2008) Adiós a la razón. Madrid: Tecnos.

Freud, Sigmund (2013). Psicoanálisis del arte. Madrid: Alianza editorial.

González Requena, Jesús (1992). S. M. Eisenstein. Lo que solicita ser escrito. Madrid: Cátedra.

- (2006) Clásico, manierista, postclásico. Los modos del relato en el cine de Hollywood. Valladolid: Castilla Ediciones.

Habermas, Jürgen (2009). Ciencia y técnica como "ideología". Madrid: Tecnos.

Hofstadter, Douglas y Sander, Emmanuel (2018). La analogía. El motor del pensamiento. Barcelona: Tusquets.

Kant, Immanuel (2003). ¿Qué es Ilustración? Buenos Aires: Ed. Nova.

Lope, Víctor (2017). Ingredientes narratológicos en recientes series de éxito: incertidumbre, suspense y pulsión escópica. En Sierra Sanchez, J. (Coord.) Nuevas tecnologias audiovisuales para nuevas narrativas interactivas digitales en la era multidispositivo, 227-238. Madrid: McGraw-Hill. Disponible en: https://goo.gl/UDKTKx - (2018a). Revisando el efecto Kuleshov en la época de la pantalla omnipresente. En Marta-Lazo (Coord.) Nuevas Realidades en la comunicación audiovisual, 261-272. Madrid: Tecnos. Disponible en: https://goo.gl/uSsRb1 - (2018b). La recuperación del sujeto en los datos masivos. En Lope Salvador, V.; Marta-Lazo, C. y Gabelas Barroso, J. A. (Coord.) Investigaciones en datificación de la era digital, 137-154. Sevilla: Egregius.

Mitchell, W. J. T. (2017). ¿Qué quieren las imágenes? Una crítica de la cultura visual. Vitoria: Sans Soleil Ediciones.

Orwell, George (1983). 1984. Boston: Houghton Mifflin Harcourt.

Pasolini, Pier Paolo (2018). Todos estamos en peligro. Entrevistas e intervenciones. Madrid: Editorial Trotta.

Scruton, Roger (2010). Usos del pesimismo. El peligro de la falsa esperanza. Barcelona: 
Ariel.

Shiner, Larry (2004). La invención del arte. Una historia cultural. Barcelona: Paidós.

Van Dijk, Teun (2005) Discurso, conocimiento e ideología. Reformulación de viejas cuestiones y propuesta de algunas soluciones nuevas. CIC Cuadernos de Información y Comunicación 0(10), 285-318. Madrid: Universidad Complutense.

Disponible en: https://goo.gl/FkHJi8 
MHCJ no 9 (2) | Año 2018 - Artículo no 14 (129) - Páginas 379 a 400 - mhjournal.org

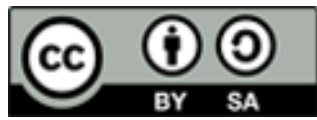

Licencia Creative Commons

Miguel Hernández Communication Journal

mhjournal.org

\section{Cómo citar este texto:}

Víctor Lope Salvador (2018): Estética e ideología en las secuencias de créditos de las series Elpuente y Mindhunter, en Miguel Hernández Communication Journal, n9 (2), pp. 379 a 400. Universidad Miguel Hernández, UMH (ElcheAlicante). DOI: http://dx.doi.org/10.21134/mhcj.v0i9.255 